\title{
Upper abdominal visceral injury resulting from blunt trauma to the pelvis: a specific variant of shockwave injury?
}

D J Emby, MB BCh, FFRAD (D) SA

AngloGold Ashanti Health, Western Deep Levels Hospital, Carletonville

Corresponding author: D Emby (demby@anglogoldashanti.com) fracture of the anterior portion of the body of the right ilium (Fig. 1). There was also a comminuted fracture of the left medial tibial plateau and evidence of a compartment syndrome involving the left calf. In addition, there was marked tenderness over the entire abdomen and intraperitoneal haemorrhage was suspected. The chest X-ray was clear and no rib fractures were shown. The patient was taken to theatre where a laparotomy revealed extensive intraperitoneal haemorrhage from a ruptured spleen. (In addition to the laparotomy, internal fixation of the left medial tibial plateau was performed; together with a medial fasciotomy of the left calf).

\section{Patient 2}

A 23-year-old man was struck on the right side of the pelvis by a large boulder following an underground rock-fall. He was haemodynamically stable on arrival in casualty. On physical examination, the right side of the pelvis was found to be unstable and a pelvic radiograph showed disruption of the right sacro-iliac joint and diastasis of the pubic symphysis (Fig. 2). As with Patient 1, the chest X-ray was clear and no rib fractures were shown. The upper abdomen was non-tender. Blood was found to be dripping from the penile meatus. A diagnosis of a ruptured (or possibly severed) urethra was made and a sonar examination was requested to examine the bladder for evidence of rupture and for localisation for the insertion of a supra-pubic catheter. On examination, the bladder was mildly distended with no visible injury to the bladder wall and no peri-vesical free fluid. Following examination of the pelvis, a full abdominal ultrasound examination was performed. A large fluid

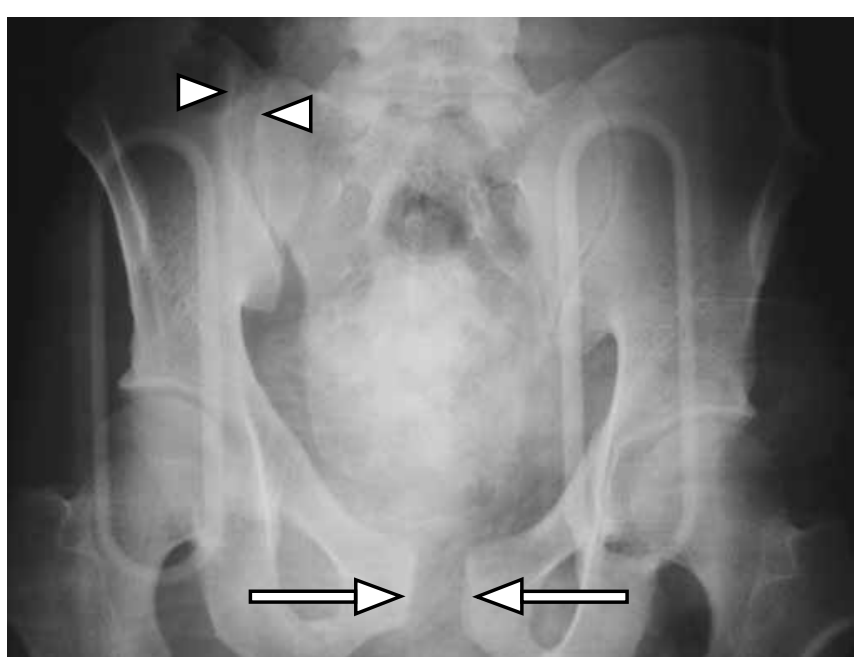

Fig. 2. Pelvic X-ray showing disrupted right sacro-iliac joint (arrow heads) and diastasis (arrows) of the pubic symphysis in patient 2. 


\section{CASE SERIES}

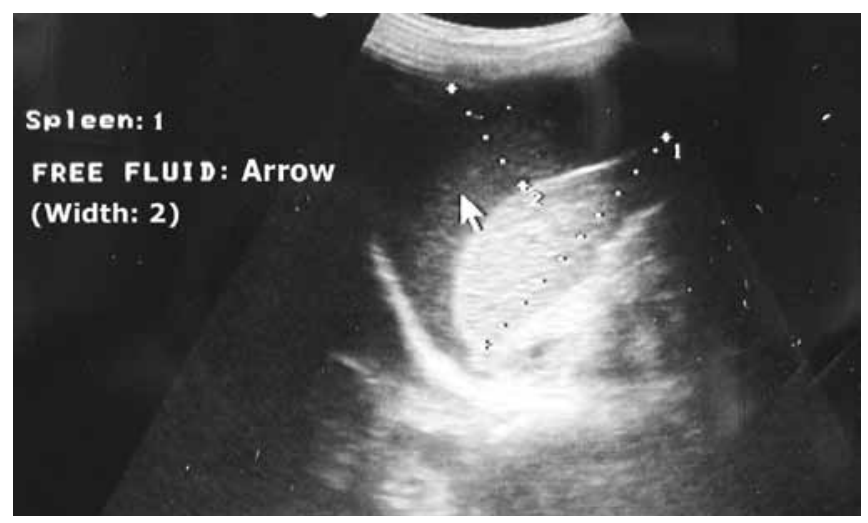

Fig. 3. Sonar image showing haematoma (arrow) around spleen.

collection (slightly echogenic, consistent with haematoma) was shown surrounding the spleen (Fig. 3). Although there was no visible splenic injury, a presumptive diagnosis of splenic rupture was made and the patient underwent immediate laparotomy. This revealed a rupture of the pancreas with extensive retroperitoneal and also intraperitoneal haemorrhage. The spleen was found to be intact.

\section{Discussion}

Tissue injury owing to the propagation of a shockwave is well described in ballistic injuries where the energy transfer from the missile to the tissue is responsible for the increased severity of the wound. ${ }^{1}$ The relationship between kinetic energy and the projectile can be derived from the following formula:

Kinetic energy $(\mathrm{KE})=0.5 \mathrm{x}$ mass $\mathrm{x}(\text { velocity })^{2}$

In the case of bullet wounds where the mass of the projectile is relatively small, the extent of the damage to the surrounding tissues is largely determined by the bullet velocity. Shockwave damage to body tissues has been described in association with blast injuries. ${ }^{2}$ In addition, shockwave injury to adjacent tissue is a well-recognised complication of extracorporeal shockwave lithotripsy. ${ }^{3}$

In the patients described above, the falling rock - although nonpenetrating - can be equated to a missile. In both these cases, the large (estimated to be between 50 and $100 \mathrm{~kg}$ ) mass, despite its relatively low velocity, had sufficient kinetic energy to cause bony pelvic injury.

In the first patient, the pelvic injury was relatively superficial and the splenic rupture could be explained by the propagation of a shockwave across the abdomen from the impact site inferiorly on the right to the left upper quadrant.

In the second patient, as the pelvic injury was predominantly retroperitoneal, it is postulated that the resulting shockwave might have propagated predominantly through the retroperitoneal tissues, resulting in the rupture of a retroperitoneal organ, i.e. the pancreas.

\section{Conclusion}

A syndromic pattern of injury is described where a direct blow to the pelvis resulted in rupture of a distant, upper abdominal viscus. Shockwave propagation across the abdomen is the likely explanation for this phenomenon. ${ }^{4}$ The possibility of injury to an upper abdominal organ should be considered in all cases where there is a severe, direct blow to the pelvis.

1. 1. Cooper GJ, Ryan JM. Interaction of penetrating missiles with tissues: some common misapprehensions and implications for wound management. Br J Surg 1990;77:606-610.

2. 2. Stapley SA, Canon LB. An overview of the pathophysiology of gunshot and blast injury with resuscitation guidelines. Current Orthopaedics 2006; 20:322-332.

3. 3. Inyckyj A, Hosking DH, Pettigrew NM, Bernstein CN. Extracorporeal shock wave lithotripsy causing colonic injury. Dig Dis Sci 1999;44(12):2485-2487.

4. 4. Salomone JA, Salomone JP. Abdominal trauma, blunt. http://emedicine.medscape.com/ article/821995-print (accessed 9 November 2010). 